\title{
A HYBRID GENETIC ALGORITHM-NEURAL NETWORK APPROACH FOR PRICING CORES AND REMANUFACTURED CORES
}

\author{
M. Seidi ${ }^{1}$ and A.M. Kimiagari ${ }^{2^{*}}$ \\ ${ }^{1}$ Department of Industrial Engineering \\ Amirkabir University of Technology, Iran \\ masoud seidi@aut.ac.ir, kimiagar@aut.ac.ir
}

\begin{abstract}
Sustainability has become a major issue in most economies, causing many leading companies to focus on product recovery and reverse logistics. Remanufacturing is an industrial process that makes used products reusable. One of the important aspects in both reverse logistics and remanufacturing is the pricing of returned and remanufactured products (called cores). In this paper, we focus on pricing the cores and remanufactured cores. First we present a mathematical model for this purpose. Since this model does not satisfy our requirements, we propose a simulation optimisation approach. This approach consists of a hybrid genetic algorithm based on a neural network employed as the fitness function. We use automata learning theory to obtain the learning rate required for training the neural network. Numerical results demonstrate that the optimal value of the acquisition price of cores and price of remanufactured cores is obtained by this approach.
\end{abstract}

\section{OPSOMMING}

Volhoubaarheid het ' $\mathrm{n}$ belangrike saak geword in die meeste ekonomieë, wat verskeie maatskappye genoop het om produkherwinning en omgekeerde logistiek te onder oë te neem. Hervervaardiging is ' $\mathrm{n}$ industriële proses wat gebruikte produkte weer bruikbaar maak. Een van die belangrike aspekte in beide omgekeerde logistiek en hervervaardiging is die prysbepaling van herwinne en hervervaardigde produkte. Hierdie artikel fokus op die prysbepalingsaspekte by wyse van ' $n$ wiskundige model.

\footnotetext{
${ }^{1}$ The author was enrolled for a PhD degree (Industrial) in the Department of Industrial Engineering, Amirkabir University of Technology.

2 The author was enrolled for a D Phil (Industrial Management) degree in the Department of Industrial Engineering, Amirkabir University of Technology.

*Corresponding author.
} 


\section{INTRODUCTION}

Reverse logistics has received increasing attention during the last decade, both in the real world and in academia, as its economic impact has become more important and as legislation has become stricter. The Reverse Logistics Executive Council provides the following widely accepted definition of reverse logistics (RL): "The process of planning, implementing, and controlling the efficient, cost effective flow of raw materials, in-process inventory, finished goods, and related information from the point of consumption to the point of origin for the purpose of recapturing value or of proper disposal" (Rogers and Tibben-Lembke [1]). We can divide the RL issue into different categories based on various methods of product recovery, such as re-use, remanufacture, and recycle (see Fig. 1).

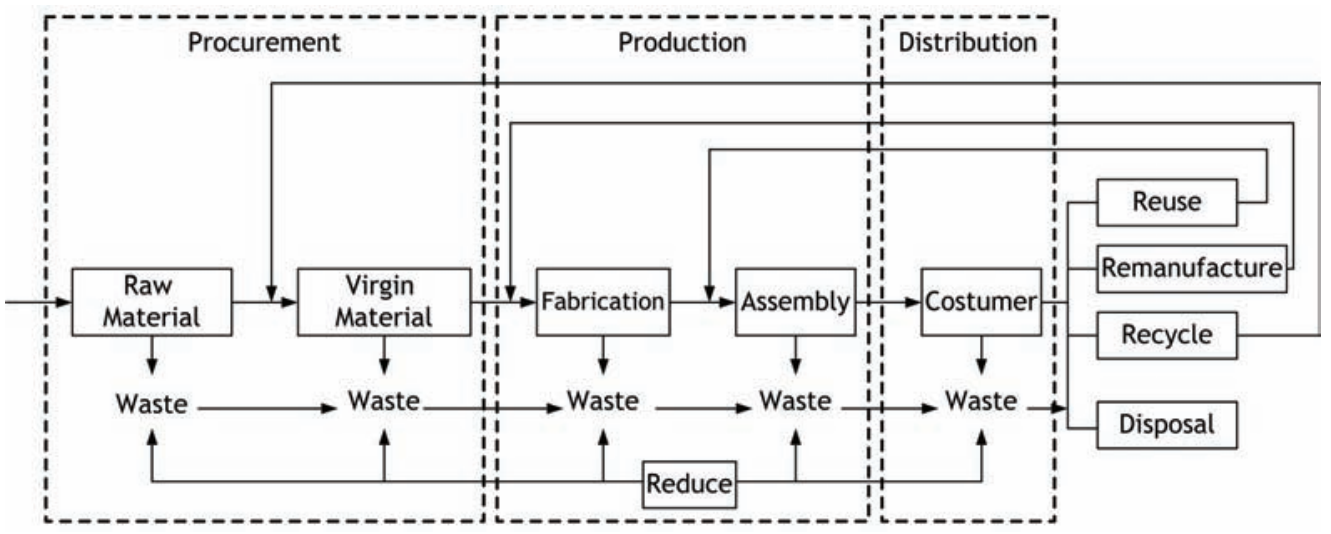

Figure 1: Operational life cycle of a product and RL role (Meade et al. [2])

Remanufacturing is a recovery option for used products. It involves activities that make remanufactured products or maj or modules marketable again and potentially as good as new. Product remanufacturing has developed rapidly in recent decades due to intensified environmental legislation and economic concerns. Through remanufacturing, products/ components that would otherwise be sent to land-fill or incineration go instead through a set of value- and material-recapturing processes, including distribution, inspection, disassembly, repair, redistribution, and remarketing or recycling. Remanufacturing allows re-usable components and recoverable materials to re-enter the supply chain for future reuse or new product fabrication (Zhang et al. [3]).

Some remanufacturing cases are widely known, such as the remanufacturing of single use cameras (Eastman Kodak and Fuji Film), toner cartridges (Xerox), photocopiers (Fuji Xerox in Australia, Netherlands, and UK), commercial cleaning equipment (Electrolux) and brand name computers (IBM in France, Germany, USA; HP in Australia). Remanufacturers are original equipment manufacturers (OEMs) who have integrated new distribution models such as leasing or 'pay per use' into remanufacturing strategies (Franke et al. [4]). Other remanufacturing practices, such as washing machines (ENVIE, France), personal computers (ReUse network, Germany), accumulators (Teldeon, Germany), cordless phones, car stereos, FM radios (Topp Companies, USA) and mobile phones (ReCellular, USA; Greener Solutions, UK) are less popular, due to the fact that OEMs are not involved, and the products are not sold through regular retail channels established by OEMs.

Remanufacturing is generally conducted under two different business strategies: the combined model and the dedicated model. Most remanufacturing operations in Europe employ the combined model. Under this strategy, remanufacturing is done by the original manufacturer, combined with its forward production. Remanufacturing in North America usually adopts the dedicated model, in which remanufacturing is outsourced to dedicated third-party remanufacturers (Patel [5]). Despite the increased application of the dedicated model in remanufacturing, hardly any theoretical and applied research efforts are directed 
to the problems associated. Most current research efforts are focused on the combined model (Thierry et al. [6]; Connelly and Koshland [7]; Ayres et al. [8]; Ferrer and Guide [9]; White et al. [10]).

There is a growing number of examples of the dedicated model in the electronics industry. OEMs such as Dell, Hewlett-Packard, and IBM, and retail stores such as CompUSA and Best Buy have outsourced their remanufacturing operations to third party providers like Noranda Recycling, Image Microsystems, and Genco. The driving force behind this trend lies in dramatically increased volume, complicated return patterns, and the increasingly complex material contents of the consumer electronic products. OEMs are no longer capable of processing the huge volume of returned post-consumer products effectively and efficiently with their own facilities. The advantages of the dedicated outsourcing model include the following: third parties are dedicated and therefore more resourceful and efficient in collecting and recovering returned products; third party providers have more expertise in product recovery processes that result in less waste and potentially the full recovery of returned products; and because third party providers are outside companies, there is no interference with the original manufacturer's production line, and thus operations are simplified. In this paper we present a dedicated model.

Remanufacturing used products is not a new term, but the scale and unique processes have made remanufacturing an important subject in research. In particular, the acquisition of used products, called cores, for remanufacturing becomes an important issue. Due to increasing pressure from legislation, inherent value cores are being collected for parts and material recovery. Before considering any recovery options for the cores, the cores must be acquired regardless of their future recovery options. In order to attract the return of cores, certain incentives have to be offered. Therefore, one of the important aspects in remanufacturing is the pricing of returned and remanufactured products (cores). In this paper, we focus on pricing the cores and remanufactured cores.

This paper is organised as follows: Related literature is reviewed in Section 2, and the proposed mathematical model and the simulation optimisation approach are given in Sections 3 and 4 respectively. Numerical results are presented in Section 5. Section 6 concludes the paper.

\section{LITERATURE REVIEW}

\subsection{Related research: Remanufacturing and acquisition of product}

Fig. 2, taken from Guide and Van Wassenhove [11], shows the relationships between the key activities in remanufacturing from a business perspective. Product acquisition is one of the few areas that management can proactively influence and, as a result, determine whether re-use activities will be economically attractive. Product acquisition is a common problem for companies offering remanufactured products in a dynamic market, where supply and demand change rapidly and on a global scale. A successful remanufacturing firm must carefully manage its product acquisition process. That is, it must buy the right quantities of the right qualities for the right prices, to maximise profits. According to Guide [12], product acquisition management acts as an interface between RL activities and production planning and control activities for firms. There are two commonly used product acquisition systems: the waste stream system, and the market-driven system (Guide and Van Wassenhove [11]; Guide and Pentico [13]).

In the waste stream, firms - encouraged by legislation - passively accept all product returns from the waste stream. On the other hand, the market-driven system employs financial incentives to encourage users to return their products to the firm. Several different kinds of financial incentive are used by firms in market-driven systems, including deposit systems, cash paid for a specified level of quality, and credit toward a new unit (Guide and Van Wassenhove [11]). The implementation of different forms of financial incentive, and their impact on the performance of the RL activities, are the main research issues in the product 
acquisition management literature. Klausner and Hendrickson [14] discuss the implementation of buy-back programmes in the power tools industry. Guide and Van Wassenhove [11] present a real-life case study to illustrate the implementation of a qualitydependent incentive policy in which pre-determined prices are offered for products with a specific nominal quality level. Guide et al. [15], Aras and Aksen [16], and Aras et al. [17] determine optimal incentive values under a quality-dependent incentive policy. Aksen et al. [18] extend Aras et al. [17] by considering a government-subsidised collection system.

An important aspect of acquisition management is pricing. In the next section, we review the literature of pricing in remanufacturing.

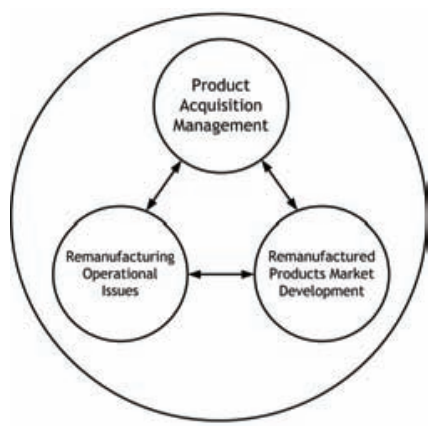

Figure 2: Product recovery management (Guide and Van Wassenhove [11])

\subsection{Related research: Pricing in remanufacturing}

The pricing problem is associated with the specific operation of remanufacturing, rather than with a generic pricing policy. Researchers have also been focusing on the study of remanufacturing for a profit (see Thierry et al. [6]). The literature on the acquisition pricing of used products, and the sales pricing of remanufactured parts/ products, is rather thin. The effectiveness of incentive mechanisms to facilitate the collection of used products is crucial to the success of a product recovery programme, and both the structure and the amount of incentive required to achieve the desired rate of product recovery are important. Although this need has been identified in several studies (Guide and Van Wassenhove [11]; Guide [12]), the number of analytical models to support this decision is relatively low.

Klausner and Hendrickson [14] present a simple mathematical model that can be used to estimate the optimal buy-back price for power tools for Bosch $\mathrm{GmbH}$. Guide et al. [15] studied the remanufacturing of cellular phones, and argued that the prices for used phones of various quality levels should consider remanufacturing requirements, as the quality of returned used phones can differ significantly. Ray et al. [19] develop the optimal pricing or trade-in strategy for remanufacturable products, considering the durability and the age distribution of products in use. The decision on core prices can be based on the deterministic remanufacturing cost for specific quality cores and the price of core products. Harrison [20], Ito [21], and Beichelt [22] discuss the Geometric Brownian Motion (GBM), its characteristics and applications in different market settings. In the investment market, the stock price is a Geometric Brownian Motion (GBM). We believe that the major mathematical studies on pricing at remanufacturing have been done by Mitra [23], Vorasayan and Ryan [24], Liang, Pokharel, and Lim [25], and Guide, Teunter, and Wassenhove [15]. In Table 1 we compare four models that are introduced by these researchers.

All the models in Table 1 are single period. In these models, the inventories that have a significant effect on prices were not discussed. Also, the purchase prices and selling prices were not considered together. In this paper, the proposed mathematical model is a multiperiod model that simultaneously determines the purchase prices, the selling price, and the inventories. The studies found in the literature make an unrealistic assumption: they 
suppose that only one remanufactured product is obtained from each returned product. This constraint is removed in the model proposed in Section 3, as it is assumed to acquire several parts from each returned product. This indicates the existence of uncertainty about the quality of returned products (cores). In the next section the proposed model will be described.

\begin{tabular}{|c|c|c|}
\hline Author & Objective function & Deterministic/ Probabilist \\
\hline Mitra & $\begin{array}{c}\text { Income } \\
\text { maximisation }\end{array}$ & Probabilistic \\
\hline \multicolumn{3}{|c|}{$\begin{array}{l}\text { Assumptions: 1) The demand is a linear function of price, 2) The inventories are divided } \\
\text { into manufactured product and remanufactured product, 3) The quality of } \\
\text { remanufactured products is classified into two levels, 4) The level of inventories is } \\
\text { determined, 5) Product will be entirely sold, 6) The number sold a decreasing function } \\
\text { of price, 7) The unsold remanufactured product can be sold off. }\end{array}$} \\
\hline Author & Objective function & Deterministic/ Probabilistic \\
\hline Vorasayan and Ryan & Profit maximisation & Probabilistic \\
\hline \multicolumn{3}{|c|}{$\begin{array}{l}\text { Assumptions: 1) The rate of return has Poisson distribution, } 2 \text { ) Rebuilt time has an } \\
\text { exponential distribution, 3) Inspection time has an exponential distribution, 4) } \\
\text { Production time has an exponential distribution, 5) Modeling with open queue network. }\end{array}$} \\
\hline Author & Objective function & Deterministic/ Probabilistic \\
\hline Liang, Pokharel and Lim & Profit maximisation & Deterministic \\
\hline \multicolumn{3}{|c|}{$\begin{array}{l}\text { Assumptions: } 1) \text { There is a time interval }[0, T] \text { between core entrance and core product } \\
\text { exit, 2) The sale price has a GBM pattern, } 3 \text { ) The entire purchased core can be used for } \\
\text { remanufacturing, 4) There are disassembly, inspection, quality assurance, logistic, } \\
\text { purchased core, and remanufacturing costs. }\end{array}$} \\
\hline Author & Objective function & Deterministic/ Probabilistic \\
\hline $\begin{array}{l}\text { Guide, Teunter and } \\
\text { Wassenhove }\end{array}$ & Profit maximisation & Deterministic \\
\hline \multicolumn{3}{|c|}{$\begin{array}{l}\text { Assumptions: 1) There is a balance between demand and return, 2) The rate of return is } \\
\text { a function of purchase price, 3) Demand is a function of sale price, 4) The number of } \\
\text { quality classes is confined, 5) Complete testing, 6) There is no fixed cost, 7) The rate of } \\
\text { return depends on the rate of sale, 8) Model is considered for single period, 9) There } \\
\text { are no constraints on demand and supply. }\end{array}$} \\
\hline
\end{tabular}

Table 1: Major studies in pricing at remanufacturing

\section{PROPOSED MATHEMATICAL MODEL}

In this section, we propose a non-linear mathematical model to optimise the acquisition price of cores, remanufactured cores, and inventory in a remanufacturing system. Our model takes advantage of combining the pricing of cores and remanufactured cores with inventory control. While conventionally suppliers compete with suppliers, factories with factories, distributors with distributors, and retailers with retailers, we change this approach in our model. In other words, competition in the market is not between companies, but between supply chains. In this paper, the whole supply chain is considered instead of only each individual element.

The model consists of a supplier, factories $\{1,2, \ldots, M\}$, a collection and disassembly centre, a distributor (central warehouse), and customers. It is remarkable that returned products (cores) are shipped from these three channels: manufacturer, distributor, and customer. It means that a product may be returned either after being used by the customer, or as defective in production or distribution processes. There is one centralised facility for collection and disassembly of cores to different factories. In our model, cores are sent to a collection and disassembly centre and sorted according to quality. Cores can be completely disassembled to primal parts. 
The central warehouse receives the demand for remanufactured cores that the factories have manufactured. Each factory can manufacture either all or part of demand. For each product the bill of materials is known. Factories acquire the materials and the parts from suppliers or from the collection and disassembly centre. They should determine the quantity of materials purchased in each period. After production in the factories, remanufactured cores are sent to the central warehouse. Upon reception, remanufactured cores are sent to customers. The central warehouse contains only final products, but it is allowed to be out of stock in the event that product levels are not sufficient to meet the demand. We assume that there are stock-out costs. Our model considers that cores are returned to the collection and disassembly centre, where they will be classified based on their quality. In our model, we examine the case of remanufacturer which acquires cores in $k$ quality classes. The first class has high quality, and the last class has low quality. With respect to their quality, they will be disassembled; and the resultant parts are prepared to be shipped to the factories, where they will be used in remanufacturing.

The production time is affected by uncertainty in the quantity and quality of cores. Therefore, one product can be produced by different processes. Cores are collected from customers via paying an acquisition price $f_{\text {itk }}$ per used product $i$ in quality group $k$ at period $t$ to the final user. We present the supply for cores with quality group $k$ from the customer channel as a linear function of acquisition price paid to customers and, thus, have $C F_{i t k}=\alpha_{i t k}+\beta_{i t k} f_{i t k}$, where $\alpha_{i t k} \geq 0, \beta_{i t k}>0$. Also, we model the demand for remanufactured cores as a linear function of the corresponding price, and thus we have $d_{i t}=a-b \times p_{i t}$ where $a, b>0$.

Our model discusses the following decisions:

a) Pricing of the cores and the remanufactured cores.

b) Determining the amount of inventories.

c) Determining the amount of purchased materials from the suppliers.

d) Determining the process for production.

The following indexes are used in the proposed model:

$a$ : the number of manufacturing processes; $\{1,2, \ldots, A\}$

$i$ : the number of product types; $\{1,2, \ldots, N\}$

$j$ : the number of factories; $\{1,2, \ldots, M\}$

$t$ : the number of programming periods; $\{1,2, \ldots, T\}$

$k$ : the number of quality groups; $\{1,2, \ldots, K\}$

$p$ : the number of materials or parts; $\{1,2, \ldots, P\}$

$l$ : the number of collection centres; $\{1,2, \ldots, L\}$

\subsection{Parameters}

We consider the following parameters:

$C_{a i j t}$ : Cost of a unit production $i$ in the factory $j$ by process $a$ at period $t$

$M R_{\text {aip }}$ : Number of the material (part) $p$ for producing a unit of product $i$ by process $a$

$H_{i j}$ : Cost of holding a unit of remanufactured core $i$ in the factory $j$

$W_{i t}$ : Cost of holding a unit of remanufactured core $i$ in the central warehouse at period $t$

$L_{j p t}$ : Cost of holding a unit of material (part) $p$ in the factory $j$ at period $t$

$S_{i t}$ : Cost of shortage of a unit of remanufactured core $i$ at period $t$

$R_{j p t}$ : Cost of purchasing a unit of material (part) $p$ in the factory $j$ at period $t$ 
$T R_{i j t}$ : Cost of transporting a unit of remanufactured core $i$ shipped from the factory $j$ to the central warehouse at period $t$

$S S_{i j}$ : Safety stock of remanufactured core $i$ in the factory $j$

$V_{j p}:$ Safety stock of material (part) $p$ in the factory $j$

$U_{j t}$ :Available time for remanufacturing in the factory $j$ at period $t$

$P T_{a i}$ : Required time for producing a unit of remanufactured core $i$ by process $a$

$B_{i j}$ : Maximum inventory of remanufactured core $i$ in the factory $j$

$C F_{i p}$ : Amountof material (part) $p$ that is obtained from core $i$

$M I_{j p}$ : Maximum inventory of material (part) $p$ in the factory $j$

$G_{p j t}$ : Cost of transporting a unit of material (part) $p$ from the collection and disassembly centre to the factory $j$ at period $t$

$H C_{p t}$ : Cost of holding a unit of material (part) $p$ at period $t$ in the collection and disassembly centre

$d_{i t}$ :Demand for remanufactured core $i$ at period $t\left(d_{i t}=a-b \times p_{i t}\right)$

$C a_{p}$ : Holding capacity of material (part) $p$ in the collection and disassembly centre

$\pi_{i p k}$ :Probability of obtaining a unit of material (part) $p$ through disassembling a unit of core

$i$ with quality $k$

$D C_{\text {iptk }}$ : Cost of disassembling material (part) $p$ from core $i$ at period $t$ with quality $k$

$f_{i t k l}^{\prime}$ : Acquisition price of core $i$ with quality $k$ at period $t$ from the collection centre $l$

$F_{t l}$ : Cost of changing the sale place of core from the current centre to centre $l$ at period $t$

$C F_{i t k}$ : Number of core $i$ delivered by the customer to the collection and disassembly centre with quality $k$ at period $t\left(C F_{i t k}=\alpha_{i t k}+\beta_{i t k} f_{i t k}\right)$

$D F_{i t k}$ : Number of core $i$ delivered by the central warehouse to the collection and disassembly centre with quality $k$ at period $t$

$M F_{i j t k}$ : Number of core $i$ delivered by the manufacturer to the collection and disassembly centre with quality $k$ at period $t$

\subsection{Variables}

We consider the following variables:

$X_{\text {aijt }}$ : Number of remanufactured core $i$ produced in the factory $j$ by process $a$ at period $t$ $X P_{j p t}$ : Amount of purchased material (part) $p$ for use in the factory $j$ at period $t$

$X Q_{i j t}$ : Number of remanufactured core $i$ shipped from the factory $j$ to the central warehouse at period $t$

$I I_{i j t}$ : Amount of remanufactured core $i$ inventory in the factory $j$ at the end of period $t$

$M_{j p t}$ : Amount of material (part) $p$ inventory in the factory $j$ at the end of period $t$

$Y B_{i t}$ : Amount of remanufactured core $i$ shortage at period $t$ in the central warehouse

$Y I_{i t}$ : Amount of remanufactured core $i$ surplus at period $t$ in the central warehouse

$O_{j p t}$ : Amount of material (part) $p$ shipped from the collection and disassembly centre to the factory $j$ at period $t$

$I I N_{p t}$ : Amount of material (part) $p$ inventory at period $t$ in the collection and disassembly centre

$f_{i t k}$ :Acquisition price of core $i$ with quality $k$ at period $t$

$p_{i t}$ : Price of remanufactured core $i$ at period $t$ 
In this model we have two objective functions: maximisation of revenue, and minimisation of costs. Therefore, the objective function is proposed as:

Minimise Z= - W1 (revenue) + W2 (costs)

Where W1 is the weight of the first objective function (revenue), and W2 is the weight of the second objective function (costs).

$$
\begin{gathered}
\text { Min } Z=-W_{1}\left[\sum_{i=1}^{n} \sum_{t=1}^{T}\left(d_{i t}-Y I_{i t}\right) p_{i t}\right]+W_{2}\left[\sum_{a=1}^{A} \sum_{j=1}^{m} \sum_{i=1}^{n} \sum_{t=1}^{T} C_{a i j t} X_{a j t}\right. \\
+\sum_{t=1}^{T} \sum_{i=1}^{n} \sum_{p=1}^{P} \sum_{k=1}^{K} \pi_{i p k}\left(C F_{i t k}+D F_{i t k}+\sum_{j=1}^{m} M F_{i j t k}\right) D C_{i p t k}+\sum_{i=1}^{n} \sum_{t=1}^{T} \sum_{k=1}^{K} C F_{i t k} f_{i t k}+\sum_{j=1}^{m} \sum_{i=1}^{n} \sum_{t=1}^{T} H_{i j} I I_{i j t} \\
+\sum_{i=1}^{n} \sum_{t=1}^{T} S_{i t} Y B_{i t}+\sum_{i=1}^{n} \sum_{t=1}^{T} W_{i t} Y I_{i t}+\sum_{j=1}^{m} \sum_{p=1}^{P} \sum_{t=1}^{T} R_{j p t} X P_{j p t}+\sum_{j=1}^{m} \sum_{p=1}^{P} \sum_{t=1}^{T} L_{j p t} M_{j p t}+\sum_{j=1}^{m} \sum_{i=1}^{n} \sum_{t=1}^{T} T R_{i j t} X Q_{i j t} \\
\left.+\sum_{j=1}^{m} \sum_{p=1}^{P} \sum_{t=1}^{T} G_{j p t} O_{j p t}+\sum_{p=1}^{P} \sum_{t=1}^{T} H C_{p t} I I N_{p t}\right]
\end{gathered}
$$

\subsection{Constraints}

We consider the following constraints:

1) Inventory equation for materials (parts) in the collection and disassembly centre

$$
\begin{gathered}
I I N_{p t}=I I N_{p(t-1)}+\sum_{i=1}^{n} \sum_{k=1}^{K} \pi_{i p k}\left(\alpha_{i t k}+\beta_{i t k} f_{i t k}\right) C F_{i p}+\sum_{i=1}^{n} \sum_{k=1}^{K} \pi_{i p k}\left(D F_{i t k}+\sum_{j=1}^{m} M F_{i j k}\right) C F_{i p}-\sum_{j=1}^{m} O_{j p t} \\
; p=1, \ldots, P, t=1, \ldots, T
\end{gathered}
$$

(1) Control of shipment

$$
\sum_{j=1}^{m} O_{j p t} \leq I I N_{p(t-1)} \quad ; p=1, \ldots, P, t=1, \ldots, T
$$

(2) Inventory capacity for the materials (parts) in the collection and disassembly centre

$$
I I N_{p t} \leq C a_{p} \quad ; p=1, \ldots, P, t=1, \ldots, T \quad \text { ) }
$$

(3) Inventory equation for the materials (parts) in the factory

$$
M_{j p t}=M_{j p(t-1)}+X P_{j p t}-\left[\sum_{i=1}^{n} \sum_{a=1}^{A} M R_{a i p} X_{a i j t}\right]+O_{j p t} \quad ; j=1, \ldots, m, t=1, \ldots, T, p=1, \ldots, n
$$

(4) Inventory capacity for the materials (parts) in the factory

$$
V_{j p} \leq M_{j p t} \leq M I_{j p} \quad ; j=1, \ldots, m, t=1, \ldots, T, p=1, \ldots, P
$$

(5) Control of the materials (parts)

$$
\sum_{a=1}^{A} \sum_{i=1}^{n} M R_{\text {aip }} X_{\text {aijt }} \leq M_{j p(t-1)}+X P_{j p t} \quad ; j=1, \ldots, m, t=1, \ldots, T, p=1, \ldots, P
$$

(6) Inventory equation for remanufactured cores

$$
I I_{i j t}=I I_{i j(t-1)}+\sum_{a=1}^{A} X_{a i j t}-X Q_{i j t}-\sum_{k=1}^{K} M F_{i j t k} \quad ; i=1, \ldots, n, j=1, \ldots, m, t=1, \ldots, T
$$

(7) Shipment control

$$
\sum_{a=1}^{A} X_{a i j t}+I I_{i j(t-1)} \geq X Q_{i j t}+\sum_{k=1}^{K} M F_{i j t k} \quad ; i=1, \ldots, n, j=1, \ldots, m, t=1, \ldots, T
$$

(8) Inventory capacity for the remanufactured cores in the factory

$$
S S_{i j} \leq I I_{i j t} \leq B_{i j} \quad ; i=1, \ldots, n, j=1, \ldots, m, t=1, \ldots, T
$$

(9) Stock out or inventory units in the central warehouse

$$
Y I_{i(t-1)}+Y B_{i(t-1)}+\sum_{j=1}^{m} X Q_{i j t}-d_{i t}-\sum_{k=1}^{K} D F_{i t k}=Y I_{i t}+Y B_{i t} \quad ; i=1, \ldots, n, t=1, \ldots, T
$$


(10) Production capacity

$$
\sum_{a=1}^{A} \sum_{i=1}^{n} P T_{a i} X_{a i j t} \leq U_{j t} \quad j=1, \ldots, m, t=1, \ldots, T
$$

(11) Maximum of the acquisition price

$$
f_{i t k} \leq f_{i t k l}^{\prime}+F_{t l} \quad i=1, \ldots, n, t=1, \ldots, T, k=1, \ldots, K, l=1, \ldots, L
$$

(12) Minimum of the price of remanufactured core

$$
p_{i t} \geq \sum_{p=1}^{P} R_{j p t}+\max \left\{C_{a j t}\right\}+T R_{i j t} \quad i=1, \ldots, n, t=1, \ldots, T, j=1, \ldots, m
$$

In pricing cores of various qualities, we have to pay attention to the fact that the vendor of cores can sell these products to other collection centres if their purchasing price is higher than ours. However, this choice has some costs for the vendor, such as transportation costs to more distant collection centres. So our price for cores should be lower than the prices of other vendors, along with the cost of changing the sale place from our centre to their centres $\left(F_{t l}\right)$. This subject is presented in constraint 12 . For the sake of brevity, we do not explain the other constraints. Since this model does not consider many uncertainties, we propose an effective simulation optimisation approach in the next section.

\section{SIMULATION OPTIMISATION: AN EFFECTIVE APPROACH FOR CONSIDERING UNCERTAINTY IN A REMANUFACTURING SYSTEM}

The problem of determining the best combination of input variables with the complex form of the objective function often arises in practice. Due to the complicated analysis, it is not possible, or at best it is difficult, to build a mathematical model of the problem studied. In such cases, model simulation is the only way to estimate the objective value. So far, simulation optimisation has been widely researched, and many approaches have been developed. Our proposed simulation optimisation is illustrated in Fig. 3.

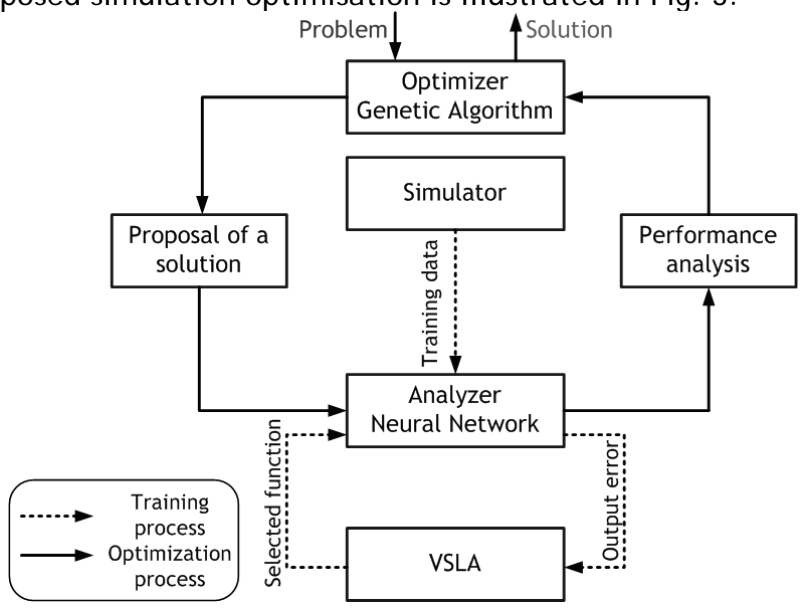

Figure 3: Proposed simulation optimisation approach

\subsection{Simulation model}

In order to have an effective approach to considering the uncertainty in a remanufacturing system, the following requirements need to be satisfied in the model:

- Uncertainty in return time, quality, and quantity of returned cores.

- Uncertainty in process times (inspection, disassembly and remanufacturing processes).

- Uncertainty in waiting time at the central warehouse. 
Instead of using the mathematical model that was introduced in section 3, we propose the simulation optimisation approach, in which appropriate data is generated for training the neural network by a simulation model (see Fig. 4.). As shown in this figure, the above requirements can be satisfied. As with the mathematical model, here we consider the quantity of returned cores and demand for remanufactured cores as a linear function of the acquisition price of cores and the price of remanufactured cores respectively. Return, process, and waiting time are modeled by random variables, as shown in Fig. 4.

For a given acquisition price of cores and price of remanufactured cores, the overall cost (introduced in the mathematical model) is obtained in the simulation model. The total cost is broken down into five general cost categories:

$$
\mathrm{TC}=\mathrm{CC}+\mathrm{CL}+\mathrm{CM}+\mathrm{CH}+\mathrm{CF}
$$

Where:

- $\quad$ CC is the product collection cost. This includes the purchasing cost of used products from customers and the transportation cost during the collection process.

- $\mathrm{CL}$ is the logistics cost. This is incurred during distribution and redistribution of the collected cores. When the receiving inventory is full, redistribution cost is incurred in the re-transportation of cores to other remanufacturing facilities.

- $\quad \mathrm{CM}$ is the remanufacturing processing cost. This includes labour costs, materials costs, and utilities costs, which are incurred in machine operating, lines switch and setup, and line and operator idling.

- $\mathrm{CH}$ is the inventory holding cost, which is incurred by holding cores in the inventory area and the production line.

- $\quad$ CF is the fixed cost of running the factory regardless of the production level. This includes general utilities, air-conditioning, insurance, and facility depreciation.

By running the simulation model as often as required, we can generate enough data to train the neural network.

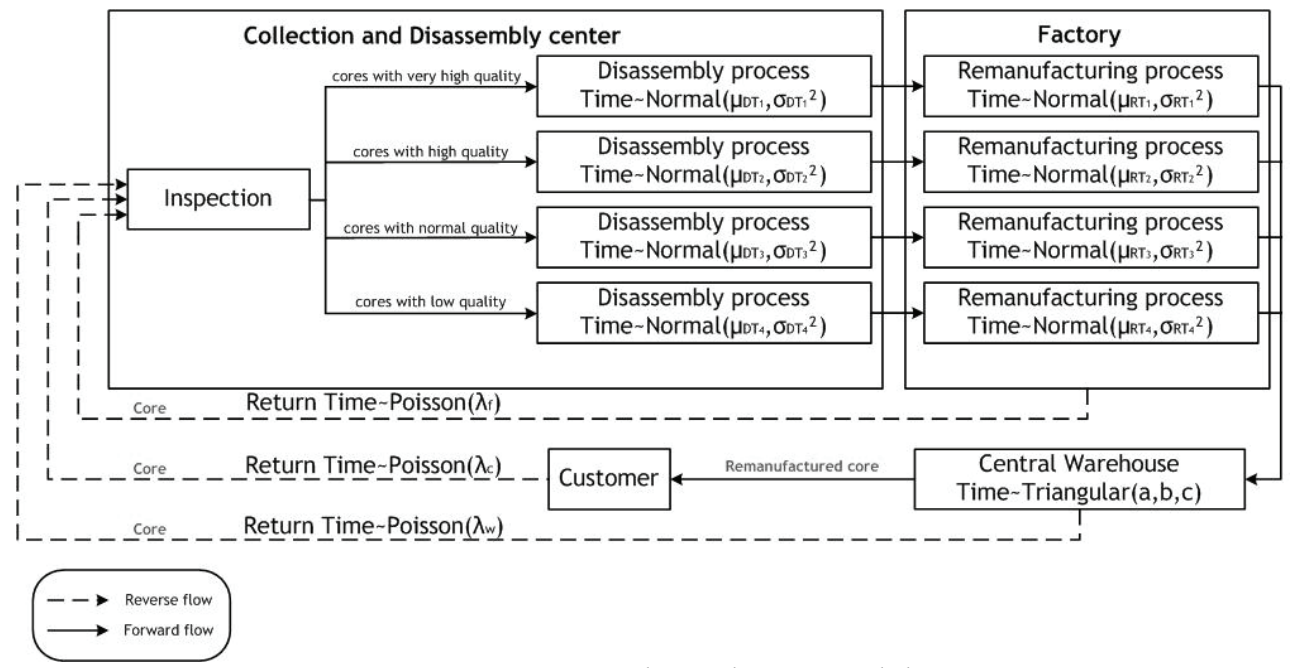

Figure 4: A general simulation model

\subsection{Hybrid genetic algorithm-neural network method}

The target neural network is trained using a given data set. This set, which consists of input and corresponding output vectors, is obtained from the simulation model that has been explained in Section 4.1. In addition to the given data set, another parameter, a learning rate, is required for neural network training that is obtained in section 4.3. The trained 
neural network works as the fitness function in the context of the genetic algorithm employed in this paper. The importance of genetic algorithms (GAs) as powerful tools for optimisation has been widely shown with a variety of applications (see Paul and Canave [26]; Lee et al. [27]; Wang [28]). The GA in this paper optimises the acquisition price of cores and the price of remanufactured cores as decision variables to minimise the overall cost of the remanufacturing system. Obtaining the optimised acquisition price of cores and remanufactured cores in the GA, they are fed into a simulation model to acquire inventory levels in the remanufacturing system. Optimisation is performed as in algorithm 1.

Algorithm 1: Hybrid GA-NN-VSLA

Begin

1. Initialisation

1.1 Parameter setting( $\mathrm{Pc}$, Pm, Stop criteria, Pop size, Selection strategy, Crossover op, Mutation op, Num Gen)

1.2 Initialisation population (Randomly)

2. Fitness evaluation(Neural network- Variable structure learning automata)

Repeat/*New generation/*

3. Individual selection for the mating pool(size of mating pool=Pop size)

4. For each consecutive pair apply crossover with probability Pc

5. Mutate children (for each new-born apply mutation with probability $\mathrm{Pm}$ )

6 . Replace the current population by the resulting mating pool

7. Fitness evaluation(Neural network- Variable structure learning automata)

Until stopping criteria is met

End

End for

\subsection{Learning automata}

Learning automata (LA) is an abstract model that can perform some function. Each selected function is evaluated by a random environment, and one response is sent to LA. LA uses this response, and the function for the next stage is selected. The relationship between LA and the random environment is shown in Fig. 5.

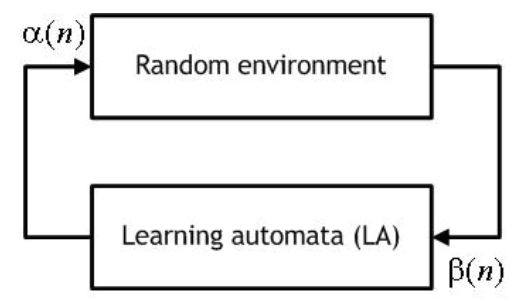

Figure 5: The relationship between LA and random environment

Environment is denoted by the triple set $E \equiv\{a, B, c\}$ where $a \equiv\left\{a_{1}, a_{2}, \ldots, a_{r}\right\}, B \equiv\left\{B_{1}, B_{2}, \ldots\right.$, $\left.B_{m}\right\}$ and $c \equiv\left\{c_{1}, C_{2}, \ldots, C_{r}\right\}$ represents input, output, and fine probability respectively. If $B$ is a set with two members, then we can say that the environment is a P-type. Also, the binary parameter $B$ is considered as a fine/reward indicator. We denote a fine by $B=1$ and $a$ reward by $B=0$. In a $Q$-type environment, $B$ has a discrete value in range $[0,1]$, and in an $S-$ type environment, $B$ is a random variable in range $[0,1]$. Moreover, $c_{i}$ shows the unfavourable result probability of $a_{i}$ function. In other words, $c_{i}=\operatorname{prob}\left\{B(k)=1 \mid a(k)=a_{i}\right\}$. In a stationary environment, $c_{i}$ has a fixed value, and in a non-stationary environment it varies over time. Therefore there are two types of LAs: fixed structure learning automata (FSLA), and variable structure learning automata (VSLA). While for FSLA cis are fixed, they are variable for VSLA.

LA can be used to adjust neural network parameters. In this paper, we adjust the neural network learning rate via VSLA. The neural network acts as environment. Learning rate (LR) 
and output error of the neural network are considered as input and output respectively (see Fig. 6).

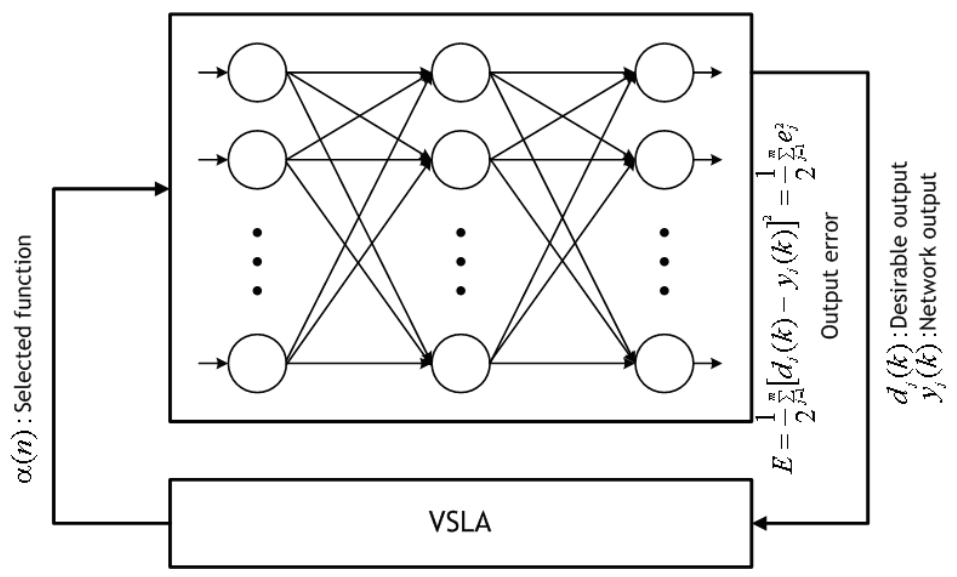

Figure 6: The relationship between VSLA and neural network

At first, the weights of the neural network mentioned in Section 4.2 are generated randomly. In fact, each learning rate varies based on the considered functions in the VSLA. We consider function set $a=\left\{a_{i}\left(R_{i}, F V_{i}\right) \mid i=1,2, \ldots, N\right\}$ and corresponding selecting probability set $P=\left\{P_{i} \mid i=1,2, \ldots, N\right\}$, where each $a_{i}$ is associated with probability $P_{i}$. Moreover, $R V_{i}$ and $F_{i}$ denote the values of the reward and fine in function $a_{i}$. The selecting probability set is updated after a number of iterations, named automata periods and denoted by AutoT. Adj usting the learning rate is performed as in algorithm 2.

\section{Algorithm 2: VSLA}

1. Set $n=1$ and AutoT $=a$. Initialise selecting probability set $P=\left\{P_{i} \mid P_{i}(n)=1 / N, i=1,2, \ldots, N\right\}$, $L R(n)$ and define function set $a=\left\{a_{i}\left(R V_{i}, F V_{i}\right) \mid i=1,2, \ldots, N\right\}$.

2. Based on set $P$, realise one function in $a, a_{j}(n)$.

3. Do $\{$ Train neural network with $L R(n)\}$.

4. Obtain the corresponding output error $E(n)$.

5. If $E(n) \leq E_{0}$ then $L R(n+1)=L R(n) \cdot R V$.

6. Else $L R(n+1)=L R(n) \bullet F V$.

7. if $n \%$ AutoT $=0$

8. $E_{j}(n)=\min (E(n-$ AutoT: $n))$.

9. If $E_{j}(n) \leq E_{0}$ then $P_{j}(n+1)=P_{j}(n) \cdot R V$.

10. Else $P_{j}(n+1)=P_{j}(n) \bullet F V$.

11. Define $R R=\left(1-P_{j}(n+1)\right) /\left(1-P_{j}(n)\right)$.

12. $P_{i}(n+1)=P_{i}(n) \cdot R R$ for all $i \neq j$.

13. Based on set $P$, realise one function in $a, a_{j}(n)$.

14. end if

15. $n=n+1$.

16. While ( $\mathrm{n} \leq$ epoch number).

Fig. 7 demonstrates how the selecting probability set is updated. After each AutoT of this algorithm, one $a_{i}$ is realised based on the current selecting probability, as in line 13. After the learning, the neural network calculates the corresponding output error $E_{j}$. At line 10 and 11 , probability $P_{j}$ is renewed based on this error. If $E_{j}$ is less than a predetermined value $\left(E_{0}\right), P_{j}$ is multiplied by a reward value, $R V>1$. Otherwise, it is multiplied by a fine value, $0 \varangle \mathrm{V}<1$. Based on this modification, the selecting probability values are changed accordingly, as in lines 11 and 12 . 


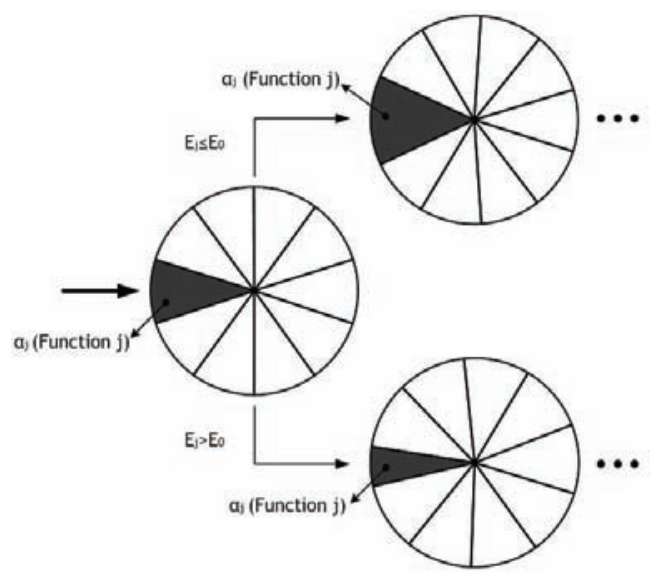

Figure 7: Update the selecting probability set

\section{NUMERICAL RESULTS}

We consider an example with the following configuration to evaluate the performance of the proposed approach. First, a data set with 140 entries is generated by the simulation model (see Fig. 8). The simulation model is developed in Arena 10.0, provided by Rockwell Software. Input data into the neural network is normalised by the following equation in order to lie in the range $(0,0.9)$ :

Normalised_data_vector $=($ data_vector*0.8+max[data_vector $] * 0.1$ -

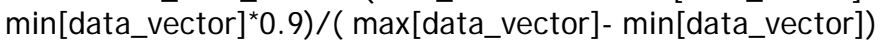

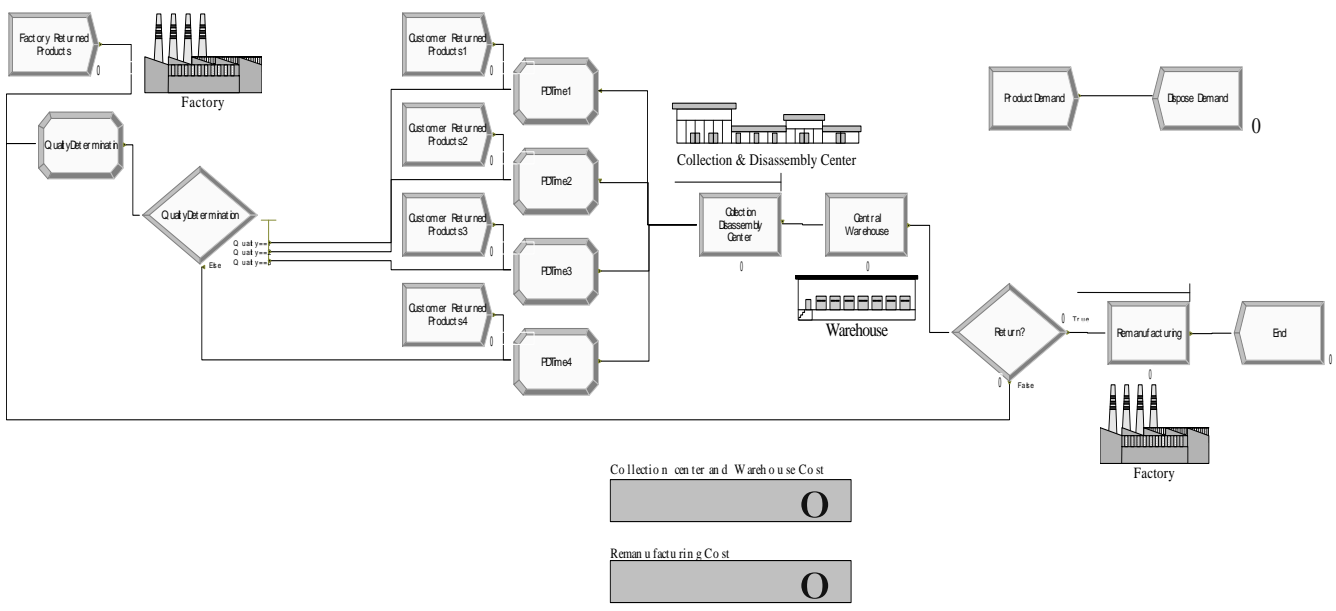

Figure 8: The simulation model

This generated data is used to train the neural network. The structure of the employed neural network is given in Fig. 9. As can be seen, this network has three layers with 5, 8 and 4 neurons respectively. The activation functions in these layers are considered as sigmoid, except for the output layer, which is linear. We can consider LR as either upper bounded, in the range $(0,3)$ in this case, or unbounded. We use a back propagation algorithm for learning. 


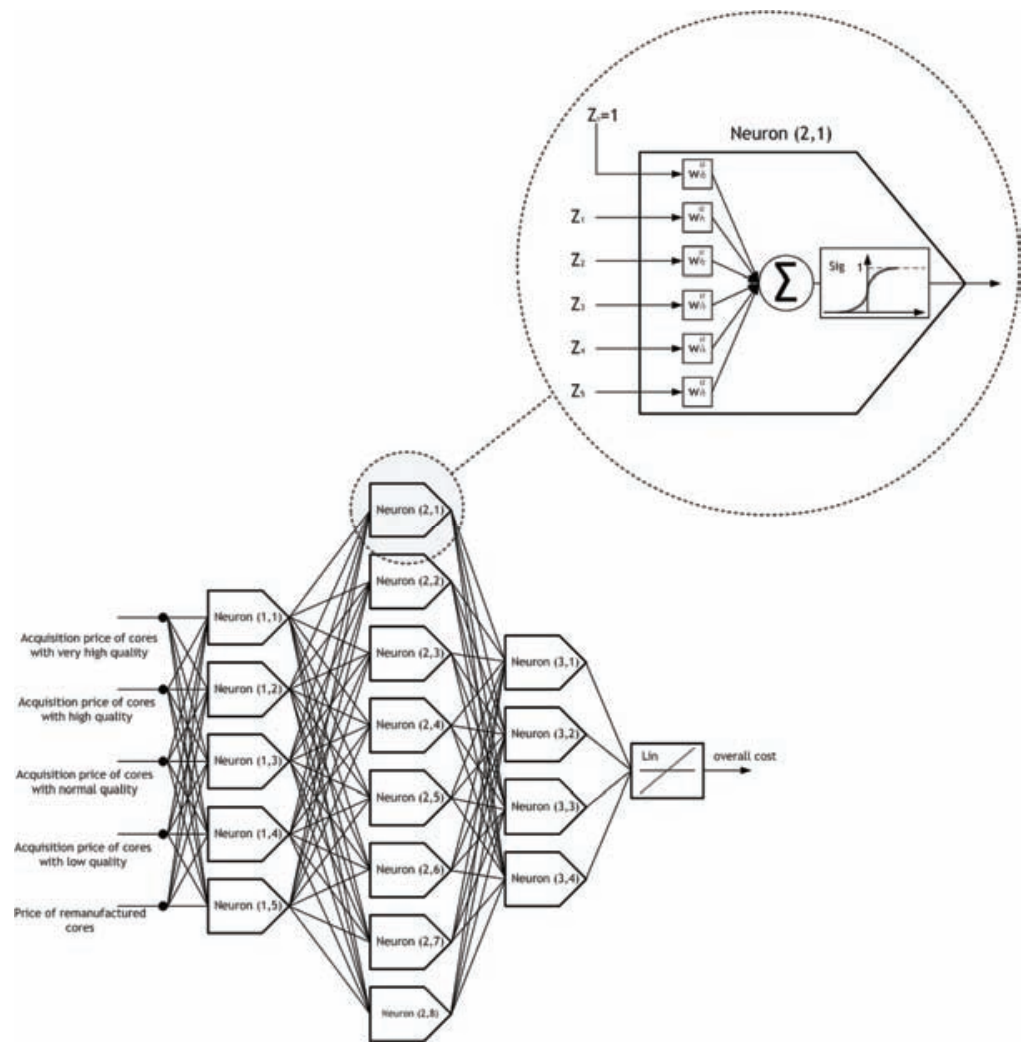

Figure 9: The neural network

Automata functions that determine RV and FV parameters are given in Table 2.

\begin{tabular}{|c|c|c|c|c|c|c|c|c|c|c|}
\hline Function & 1 & 2 & 3 & 4 & 5 & 6 & 7 & 8 & 9 & 10 \\
\hline RV & 1.04 & 1.04 & 1.04 & 1.05 & 1.05 & 1.05 & 1.06 & 1.06 & 1.06 & 1.07 \\
\hline FV & 0.6 & 0.7 & 0.8 & 0.6 & 0.7 & 0.8 & 0.6 & 0.7 & 0.8 & 0.6 \\
\hline
\end{tabular}

Table 2: Automata functions

Output error for the bounded and unbounded LR is shown in Fig. 10 and Fig. 11 respectively.
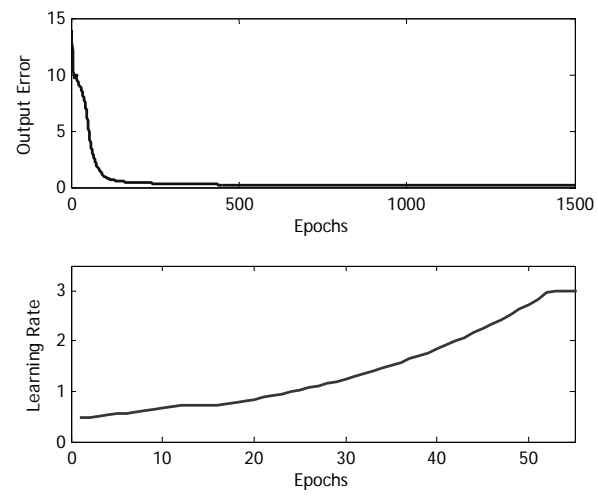

Figure 10: Output error and bounded LR 
As shown in Fig. 10, the value of output error converges to 0.1269 after approximately 500 epochs. As a result, the learning rate always increases up to its upper bound.
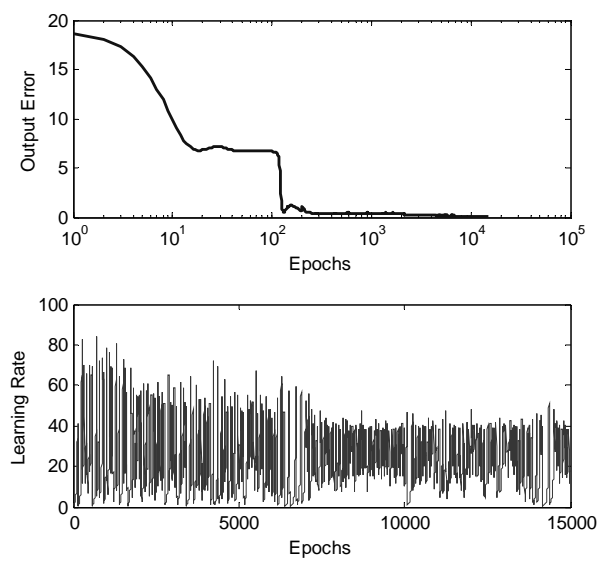

Figure 11: Output error and unbounded LR

For the case of the unbounded learning rate in Fig. 11, while convergence occurs after more epochs (approximately 1,000 epochs) compared with Fig. 10, the output error is 0.0671, which is smaller than in the bounded case. In addition, the learning rate demonstrates decaying oscillation. The neural network trained with bounded LR is used as a fitness function in the GA. The parameters of the GA are as follows:

$P c=0.4, P m=0.2$, Stop criteria=difference between best solution in different generation, Pop size $=50$, Selection strategy=roulette wheel selection, Crossover op=uniform, Mutation $o p=s w a p$, Encoding $=$ real numbers, and Evaluation function=NN-VSLA.

The best solution at each generation, which is inversely proportional to the cost function in $\mathrm{GA}$, is shown in Fig. 12. The final optimised solution at generation 8 is given in Table 3.

\begin{tabular}{|c|c|c|c|c|c|}
\hline $\begin{array}{c}\text { Acquisition } \\
\text { price of } \\
\text { cores with } \\
\text { low } \\
\text { quality }\end{array}$ & $\begin{array}{c}\text { Acquisition } \\
\text { price of } \\
\text { cores with } \\
\text { normal } \\
\text { quality }\end{array}$ & $\begin{array}{c}\text { Acquisition } \\
\text { price of } \\
\text { cores with } \\
\text { high } \\
\text { quality }\end{array}$ & $\begin{array}{c}\text { Acquisition } \\
\text { price of } \\
\text { cores with } \\
\text { very high } \\
\text { quality }\end{array}$ & $\begin{array}{c}\text { Price of } \\
\text { remanufactured } \\
\text { cores }\end{array}$ & $\begin{array}{c}\text { Overall } \\
\text { Cost }\end{array}$ \\
\hline 0.35 & 1.26 & 1.5 & 3.5 & 19.37 & 3089.1 \\
\hline
\end{tabular}

Table 3: Final solution

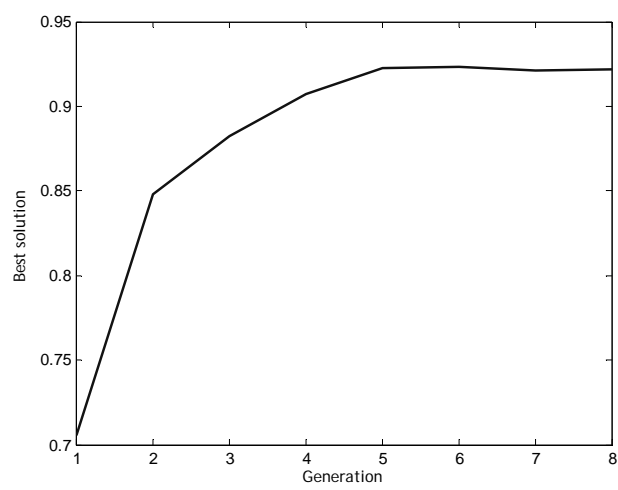

Figure 12: Best solution in each generation 
Table 4 shows different configurations of the neural network along with corresponding errors. The final optimised solutions of these configurations are given in Table 5.

\begin{tabular}{|c|c|c|c|c|c|c|c|}
\hline \multirow[b]{2}{*}{$\begin{array}{c}\text { Network } \\
\text { configuration }\end{array}$} & \multirow{2}{*}{$\begin{array}{l}\text { Neurons } \\
\text { in } \\
\text { different } \\
\text { layers }\end{array}$} & \multirow[b]{2}{*}{$\begin{array}{l}\text { Activation } \\
\text { function }\end{array}$} & \multirow[b]{2}{*}{ Epochs } & \multirow[b]{2}{*}{ AutoT } & \multicolumn{2}{|c|}{ LR } & \multirow[b]{2}{*}{ Error } \\
\hline & & & & & limited & unlimited & \\
\hline $\mathrm{NCl}$ & 5-8-4-1 & $\begin{array}{l}\text { sig- sig sig- } \\
\text { lin } \\
\end{array}$ & 1500 & 10 & • & & 0.1269 \\
\hline NC2 & 5-8-4-1 & $\begin{array}{l}\text { sig- sig sig- } \\
\text { lin }\end{array}$ & 15000 & 40 & • & & 0.0832 \\
\hline NC3 & 5-8-4-1 & $\begin{array}{l}\text { sig- sig sig- } \\
\text { lin }\end{array}$ & 15000 & 40 & & • & 0.0671 \\
\hline NC4 & 5-8-4-1 & $\begin{array}{l}\text { sig- ssig } \\
\text { sig- lin }\end{array}$ & 1500 & 10 & • & & 0.0951 \\
\hline NC5 & 5-8-4-1 & $\begin{array}{l}\text { sig- ssig } \\
\text { sig- lin }\end{array}$ & 1500 & 10 & & • & 0.0808 \\
\hline NC6 & 5-8-4-1 & $\begin{array}{l}\text { sig- ssig } \\
\text { sig- lin }\end{array}$ & 15000 & 40 & $\bullet$ & & 0.1243 \\
\hline
\end{tabular}

Table 4: Network configuration and their errors (NN-VSLA results)

\begin{tabular}{|c|c|c|c|c|c|c|}
\hline $\begin{array}{c}\text { Network } \\
\text { configuration }\end{array}$ & $\begin{array}{c}\text { Acquisition } \\
\text { price of } \\
\text { cores with } \\
\text { low } \\
\text { quality }\end{array}$ & $\begin{array}{c}\text { Acquisition } \\
\text { price of } \\
\text { cores with } \\
\text { normal } \\
\text { quality }\end{array}$ & $\begin{array}{c}\text { Acquisition } \\
\text { price of } \\
\text { cores with } \\
\text { high } \\
\text { quality }\end{array}$ & $\begin{array}{c}\text { Acquisition } \\
\text { price of } \\
\text { cores with } \\
\text { very high } \\
\text { quality }\end{array}$ & $\begin{array}{c}\text { Price of } \\
\text { remanufactured } \\
\text { cores }\end{array}$ & $\begin{array}{c}\text { Overall } \\
\text { Cost }\end{array}$ \\
\hline NC1 & 0.35 & 1.26 & 1.50 & 3.5 & 19.37 & 3089.1 \\
\hline NC2 & 0.20 & 0.61 & 1.12 & 3.5 & 20 & 3088.96 \\
\hline NC3 & 0.25 & 0.40 & 1.50 & 2.89 & 20 & 3082.66 \\
\hline NC4 & 0.29 & 0.33 & 1.04 & 2.13 & 18.40 & 3404.75 \\
\hline NC5 & 0.37 & 1.36 & 2.84 & 3.34 & 18.14 & 3404.75 \\
\hline NC6 & 0.29 & 0.84 & 1.02 & 1.33 & 18.11 & 3404.75 \\
\hline
\end{tabular}

Table 5: Network configuration and their final solution (GA results)

Observing different configurations in both tables, we see that NC3 with the smallest output error achieves the smallest overall cost value.

\section{CONCLUSION}

Remanufacturing is a recovery option for used products in reverse logistics. Remanufacturing is the process by which used products are recovered, processed, and sold as new ones. It introduces a host of issues related to product design, production planning, inventory control, logistics, information systems, marketing, pricing, and quality control. As remanufacturing requires a continuous supply of used products, an economic incentive is required to attract customers to return their used products (called cores), and the problem of pricing a core becomes an important issue. Thus, the devising of a core pricing policy is critical to remanufacturing, as it is also the beginning of the remanufacturing.

Such a pricing problem is analogous to pricing an option that can be used to sell the remanufactured cores. Uncertainty in the problem of remanufacturing pricing prevents the mathematical model from satisfying the necessary requirements. We have dealt with this problem by using a simulation optimisation approach that leads to an improved acquisition price for cores and for remanufactured cores. This approach, by employing a GA based on an NN as fitness function, can overcome the complexity and uncertainty of this problem more effectively. Moreover, the automata theory has been a powerful tool for neural 
network training. Using an unbounded learning rate in learning automata leads to achieving less network error and a more appropriate price. Likewise, regarding the complexity of pricing problems in remanufacturing systems and of optimising prices, the use of a Meta heuristic algorithm is suggested. In this paper, widely applied Meta heuristic and simulation algorithms were combined and applied, which led to the effective modeling of uncertainties embedded in pricing.

\section{REFERENCES}

[1] Rogers, D.\&Tibben-Lembke, R. 1999. Going backward: Reverse logistics trends and practices. Reverse Logistics Executive Council, Reno, NV.

[2] Meade, L., Sarkis, J. \& Presley, A. 2007. The theory and practice of reverse logistics, International Journal of Logistics Systems and Management, 3, pp 56-84.

[3] Zhang, H.C., Li, J., Shrivastava, P. \& Whitley, A. 2004. A web-based system for reverse manufacturing and product environmental impact assessment considering end-of-life dispositions. CIRP Annals Manufacturing Technology, 53(1), pp 5-8.

[4] Franke, C., Basdere, B., Ciupek, M. \& Seliger, S. 2006. Remanufacturing of mobile phones-capacity: Program and facility adaptation planning, Omega, 34, pp 562-570.

[5] Patel, G.S. 2006. A stochastic production cost model for remanufacturing systems. M.S. Thesis, the University of Texas-Pan American, USA.

[6] Thierry, M., Salomon, M., van Nunen \& J., van Wassenhove, L. 1995. Strategic issues in product recovery management, California Management Review, 37 (2), pp 114-135.

[7] Connelly, L. \& Koshland, C. 1997. Two aspects of consumption: Using an energybased measure of degradation to advance the theory and implementation of industrial ecology, Resources, Conservation, and Recycling, 19, pp 199-217.

[8] Ayres, R., Ferrer, G. \& Leynseele, T. 1997. Eco-efficiency, asset recovery, and remanufacturing, European Management Journal, 15 (5), pp 557-574.

[9] Ferrer, G., Guide, V.D.R. 2002. The handbook of industrial ecology, Elgar Academic Publishers, Burke, AE.

[10] White, C.D., Masanet, E., Rosen, C.M. \& Beckman, S.L. 2003. Product recovery with some byte: An overview of management challenges and environmental consequences in reverse manufacturing in the computer industry, Journal of Cleaner Production, 11, pp 445-458.

[11] Guide, V.D.R. \& Van Wassenhove, L.N. 2001. Managing product returns for remanufacturing, Production and Operations Management, 10 (2), pp 142-155.

[12] Guide, V.D.R. 2000. Production planning and control for remanufacturing: Industry practice and research needs, Journal of Operations Management, 18, pp 467-483.

[13] Guide, V.D.R. \& Pentico, D.W. 2003. A hierarchical decision model for remanufacturing and re-use, International Journal of Logistics: Research \& Applications, 6, pp 29-35.

[14] Klausner, M. \& Hendrickson, C. 2000. Reverse-logistics strategy for product takeback, Interfaces, 30 (3), pp 156-165.

[15] Guide, V.D.R., Teunter, R.H. \& van Wassenhove, L.N. 2003. Matching demand and supply to maximize profits from remanufacturing, Manufacturing \& Service Operations Management, 5 (4), pp 303-316.

[16] Aras, N. \& Aksen, D. 2008. Locating collection centers for distance and incentive dependent returns, International Journal of Production Economics, 111, pp 316-333.

[17] Aras, N., Aksen, D. \& Tanugur, A.G. 2008. Locating collection centers for incentive dependent returns under a pick-up policy with capacitated vehicles, European Journal of Operational Research, 191, pp 1223-1240.

[18] Aksen, D., Aras, N. \& Karaarslan, A.G. 2009. Design and analysis of government subsidized collection systems for incentive-dependent returns, International Journal of Production, 119, pp 308-327.

[19] Ray, S., Boyacı, T. \& Aras, N. 2005. Optimal prices and trade-in rebates for durable, remanufacturable products, Manufacturing and Service Operations Management, 7 (3), pp 208-228. 
[20] Harrison, J.M. 1985. Brownian motion and stochastic flow systems. John Wiley \& Sons.

[21] Ito, K. 2004. Stochastic processes. Springer-Verlag, Berlin Heidelberg.

[22] Beichelt, F. 2006. Stochastic processes in science engineering and finance. Chapman $\&$ Hall/ CRC.

[23] Mitra, S. 2007. Revenue management for remanufactured products, Omega, 35, pp 553-562.

[24] Vorasayan, J. \& Ryan, S.M. 2006. Optimal price and quality of refurbished products, Production and Operation Management, 15, pp 369-383.

[25] Liang, Y., Pokharel, S. \& Lim, H.L. 2007. Pricing used products for remanufacturing, European Journal of Operational Research, doi: 10.1016/ j.ejor.11.029.

[26] Paul, R.J. \& Chanev, T.S. 1998. Simulation optimization using a genetic algorithm, Simulation Practice and Theory, 6, pp 601-611.

[27] Lee, S.G., Khoo, L.P. \& Yin, X.F. 2000. Optimizing an assembly line through simulation augmented by genetic algorithms, International Journal of Advanced Manufacturing Technology, 16, pp 220-228.

[28] Wang, L. 2003. Advance in simulation optimization, Control Design, 18, pp 257-262. 